\title{
Campañas contra la violencia de género: los medios en la construcción del imaginario social en jóvenes de educación media superior
}

\author{
Campaigns against gender violence: the media in the construction of a social imaginary in young \\ people in upper secondary education
}

Azul Kikey Castelli Olvera ${ }^{a}$

\begin{abstract}
:
The present work argues that the visual representations created for social advertising campaigns to prevent and address gender violence, affect the conformation of a collective imaginary about violence, which type gender violence into physical violence, separating it from a cultural problem and creating a non-attacked us and the other victims. The foregoing is based on the social advertising review to address and prevent gender-based violence both in Mexico and in the analysis with the categories of Roland Barthes, of the images created by middle school youth, during focus group sessions applied to them, during 2014, in the city of Pachuca, Hidalgo in Mexico. The main conclusions point to the fact that young people state that they have little proximity to the campaigns issued by civil institutions or associations, and that in many cases they do not feel identified with the images or slogans, yet they shape their imaginary about gender violence, without realizing it from the social advertising they consume.
\end{abstract}

Keywords:

Social advertising, gender violence, social collective.

\section{Resumen:}

El presente trabajo sostiene que las representaciones visuales creadas para las campañas de publicidad social para prevenir y atender la violencia de género, inciden en la conformación de un imaginario social sobre la violencia, que la encasilla en violencia física, desvinculándola de una problemática cultural y creando un nosotros no agredidas y las otras, víctimas. Lo anterior se sostiene en la revisión de publicidad social para atender y prevenir la violencia de género tanto en México. En este espacio se presenta el análisis, a partir de las categorías de Roland Barthes, de las imágenes creadas por jóvenes de educación media, durante sesiones de grupos focales aplicadas a estos durante 2014, en la ciudad de Pachuca, Hidalgo, México. Las principales conclusiones apuntan a que las y los jóvenes manifiestan que tienen poca cercanía con las campañas emitidas por las instituciones o asociaciones civiles, y que en muchos de los casos no se sienten identificados con las imágenes o los slogans, no obstante ellos conforman sus imaginarios sociales sobre la violencia de género, sin darse cuenta a partir de la publicidad social que consumen.

\section{Palabras Clave:}

Publicidad social, violencia de género, imaginario social

\footnotetext{
a Universidad Autónoma del Estado de Hidalgo, https://orcid.org/0000-0002-5906-5912,Email: azul_castelli@uaeh.edu.mx
} 


\section{Introducción}

Pensar la comunicación en la actualidad implica también pensar en tecnología y en medios masivos de comunicación, así como en el papel que estos juegan en la cotidianidad de los individuos, en cómo contribu yen a la adquisición de conocimientos e información sea esta verídica o deformada. La realidad es que los medios de comunicación tienen un papel preponderante en la educación informal de los sujetos y en la construcción del imaginario social, que según Castoriadis (Fernández 2017) se refiere al conjunto de significaciones que permean la visión que determinado grupo social comparte entre sí, a partir de este imaginario se conforman las relaciones sociales-materiales y sus universos de sentido.

Como plantea Morin, quien retoma la propuesta de Castoriadis y adapta su concepto a imaginario social, las significaciones se alimentan de las imágenes presentadas en los medios en un proceso cíclico, don de el medio alimenta la vida material y la vida imaginaria se alimenta del medio (Agudelo 2011).

De esta participación de los medios en la educación informal de los sujetos y de su incidencia en la conformación de ideas y prejuicios, surge uno de los temas preponderantes en la agenda feminista: La representación de las mujeres. Esta discusión está por cumplir cincuenta años, sin embargo, sobre la mesa siguen diversas problemáticas entre las que se pueden mencionar la cosificación del cuerpo de las mujeres en la publicidad, la reiteración de estereotipos de maternidad y conyugalidad y la banalización y naturalización de la violencia.

En la actualidad, ya sea en la publicidad o en la información, las imágenes que se difunden de la mujer a través de los medios, suelen ser negativas, estereotipadas, inexactas y violentas, describiéndose las mujeres más por su apariencia que por sus capacidades (López y Bernad, 2007: 1-2).

La discusión y crítica a estas representaciones se ha centrado sobre todo en la crítica a la publicidad y al uso y cosificación del cuerpo de las mujeres como objeto y mercancía, sin embargo, no se ha quedado ú nicamente en este ámbito sino que se va filtrando poco a poco a la publicidad social y a las instituciones y asociaciones civiles que desde la década de los noventa del siglo pasado, empezaron a emitir campañas para prevenir la violencia contra las mujeres.'

Estas primeras campañas ponían el acento en la violencia física y en el fomento a la denuncia, sin embargo, la principal crítica que enfrentaron fue que visibilizaban un solo tipo de violencia, su mirada era asistencial y contribuían a la revictimización de las mujeres y a un ejercicio de violencia simbólica, donde se petrificaba al sujeto representado. Es decir, a las mujeres, se les mostraba como opacas, invisibles, víctimas, entre otras acepciones, lo que contribuyó a anestesiar a una sociedad, que de tanto ver imágenes violentas termina por paralizarse ante el shock del maltrato (Fernández, 2008).

Desde esas primeras iniciativas, las campañas se han ido modificando, tendiendo a una desdramatización de las imágenes y a la emisión de mensajes en positivo. Tal es el caso de la publicidad social emitida por el Instituto Nacional de las Mujeres en las campañas de 2007-2011 (ver figura 1). En el primer cartel se observa la tendencia asistencial basada en la promoción de la denuncia mientras que en el segundo (de 2011), ya observamos la imagen de una mujer sonriente trabajando en un invernadero.

Figura 1. Carteles de las campañas de 2007 y 2011, Instituto Nacional de las Mujeres, México.

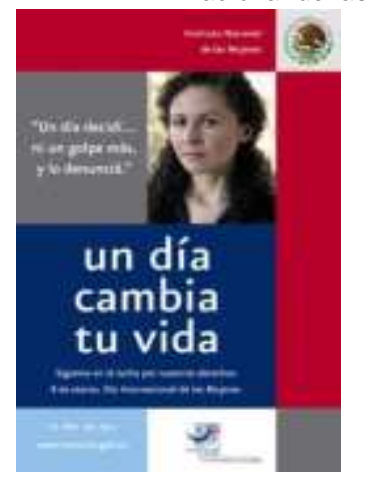

Cartel: "Por la igualdad y contra la violencia".

Fuente:http://www.inmujeres.gob.mx/index. php/trans/transparencia-focalizada/2uncategorised/61-campanias

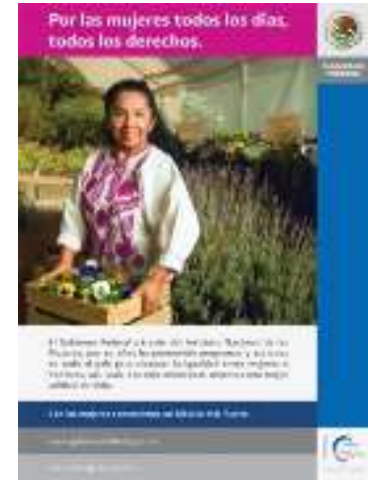

Cartel: "Por las mujeres, todos los días, todos los derechos". Fuente:

http://www.inmujeres.gob.mx/index.phptt rans/transparencia-focalizada/2uncategorised/61-campanias
Pese a que la intención es no revictimizar a las mujeres reiterando imágenes de éstas golpeadas, las campañas con mensajes positivos también son objeto de crítica, puesto que se tiende a crear imágenes incoherentes con su slogan, de este modo los rostros sonrientes no casan con la situación de violencia que viven las mujeres en la actualidad.

En agosto de 2019, la campaña emitida por la Consejería de Igualdad, Políticas Sociales y Conciliación de la jun ta de Andalucía enfrentó severas críticas:

La sucesión de crímenes de violencia de género casa mal con un anuncio en el que el concepto de malos tratos va asociado a unas mujeres sonriendo. El argumento de la Junta de Andalucía, responsable de poner en marcha la campaña donde están incluidos estos carteles, es que recoge la alegría de quienes se han beneficiado de denunciar a sus maltratadores. No lo han entendido así los partidos de la oposición en Andalucía ni las organizaciones feministas ni quienes trabajan atendiendo a las víctimas (El país, 2019).

Aunado al escandaloso costo de la campaña, que fue de 1.2 millones de euros, las críticas giran en torno al hecho de que según los grupos que se dedican a la atención de 
las mujeres víctimas de violencia, la campaña contribuye a trivializar el problema, ya que no explica las bases de género que sostienen la desigualdad entre hombres y mujeres y que coloca a estas últimas en una situación de inequidad con respecto a los hombres (El país 2019).

Figura 2. Imagen de la campaña contra la violencia implementada en Andalucía, 2019

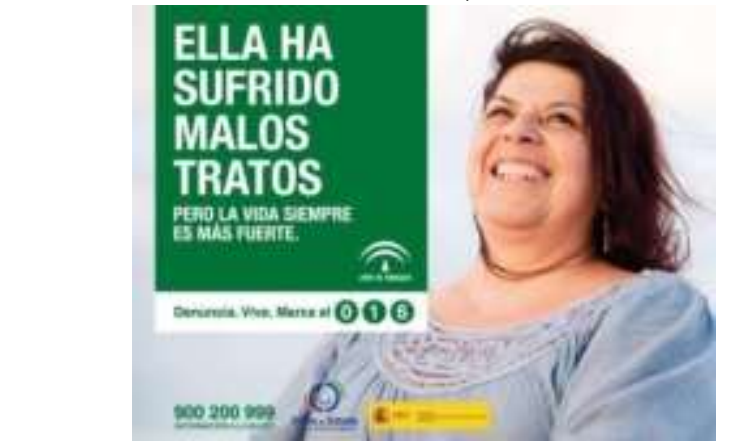

Fuente: País 2019.

A lo anterior se agrega el hecho de que las campañas enfrentan una problemática de recepción. En un estu dio realizado por Fernández (2008), donde entrevistan a mujeres sobrevivientes al maltrato y les pregunta su opinión sobre las campañas vigentes en ese momento, algunas opinaron que las campañas son demasiado "light".

Partiendo de lo anterior y considerando que los medios de comunicación masiva, en este caso las campañ as de publicidad social, para prevenir, atender y erradicar la violencia de género contribuyen a la conformación de un imaginario social en torno a esta problemática, en este trabajo se sostiene que estos productos mediáticos han conformado de manera inconsciente, un ideario entre los jóvenes, donde se concibe a las mujeres como víctimas o se invisibiliza la problemática, presentando imágenes de mujeres felices, aunado a que los jóvenes desconocen o tienen una idea errónea sobre el concepto género $y$, por lo tanto, tampoco reconocen esta problemática como social y cultural sino como individual. Lo anterior, se comprueba a través de la revisión de las campañas ya presentadas en líneas preliminares y de la recuperación a través de grupos focales de imágenes elaboradas por jóvenes que cursaban su educación media superior y que hablaron sobre su percepción sobre estos productos, que en su momento, se encontraban vigentes y elaboraron propuestas visuales sencillas sobre qué imágenes utilizarían ellos para este tipo de productos.

Cabe mencionar que la importancia de entender cómo llegan los mensajes a las y los jóvenes a través de la publicidad social, y cómo inciden en su percepción de cierta problemática, radica en que, tal y como sucede en la publicidad comercial, es necesario conocer al público al que se apela para que los mensajes sean efectivos, de lo contrario únicamente se reiteran estereotipos o se crean mensajes incoherentes con la realidad de los receptores, lo que implica una pérdida de recursos económicos, y sobre todo, de oportunidades para incidir, aunque sea de manera gradual, en el imaginario social que tiene la población, en este caso los jóvenes, sobre una problemática tan apremiante como lo es la violencia de género.

\section{Metodología}

Uno de los pasos más importantes para el desarrollo de una campaña de publicidad, sea ésta social o comercial, es conocer la opinión de los públicos respecto a las campañas emitidas, pues esto es parte del proceso de seguimiento y evaluación que considera el plan de marketing de toda campaña. En este sentido, du rante el año 2014 se realizaron una serie de grupos focales con la finalidad de evaluar la percepción que tenían jóvenes que cursaban educación media superior, respecto a la violencia de género y las campañas que buscan prevenirla, brindar atención y erradicar esta problemáticaii.

Se consideró trabajar con jóvenes debido a que la Encuesta Nacional sobre la Dinámica de Relaciones en los Hogares (ENDIREH) 2006 y la ENDIREH 2011 apuntaban que de los 15 a los 24 años de edad, se registraban los índices de violencia más altos, además se optó por este grupo de jóvenes, bajo el supuesto de que al encontrarse cursando un grado escolar de nivel medio superior, las y los jóvenes contaban con mayor información sobre qué es el género y la violencia de género y probablemente, mayor acceso a las campañas de prevención, atención y erradicación de la violencia de género que se implementaron por parte del Instituto Nacional de las Mujeres y el Instituto Hidalguense de las Mujeres en los años 2007 y 2011.

En este sentido, con la finalidad de recuperar la experiencia vivida de las y los jóvenes en edades comprendidas en el rango mencionado, se optó por trabajar con la técnica de investigación cualitativa de grupos focales, lo que permitió recuperar las opiniones de grupos heterogéneos, dando participación a todos los integrantes de manera equitativa.

La técnica de investigación de grupos focales consiste en entrevistas grupales que permiten agilizar la recolección de datos y la confrontación de ideas entre los participantes. Kitzinger (1995) señala que esta técnica permite trabajar con preguntas abiertas, recuperar las voces de los participantes desde su propio vocabulario, trabajar con personas que no saben leer o escribir, estimula la integración y participación de entrevistados que en solitario podrían presentar resistencia, pero que en grupo se atreven a comentar y participar con mayor 
disposición pues se ven estimulados por la dinámica grupal.

Por otro lado, Ramírez (2011) señala que para la preparación de grupos focales se debe considerar un tema eje y la presencia de un moderador que guía la discusión, los participantes no deben pertenecer a una misma familia o ser un grupo de amigos, lo ideal es que el grupo se integre con personas que se desconocen entre sí, pero que comparten características comunes.

El número de integrantes del grupo focal, según Krueger (1994), fluctúa entre cuatro y doce personas. Según este autor no es recomendable trabajar con grupos más amplios pues se corre el riesgo se subdividan y son más difíciles de manejar. Es por esto que en este estudio se optó por trabajar con grupos de jóvenes conformados por doce integrantes, seis mujeres y seis hombres.

Siguiendo a Ramírez, se realizaron grupos focales de doce integrantes en los que se procuró ajustarse a la logística propuesta por Escobar y Bonilla-Jiménez (2009), quienes desarrollaron una guía para grupos focales, integrada por los diez pasos, que se resumen a continuación: 1. Establecer los objetivos;2. Diseño de la investigación; 3. Desarrollo del cronograma; 4. Selección de los participantes; 5. Selección del moderador; 6. Preparación de preguntas estímulo; 7 . Selección del sitio de reunión; 8. Logística; 9. Desarrollo de la sesión; y 10. Análisis de la información.

Para la selección de las y los participantes que integraron los grupos focales se recurrió a un muestreo simple de la población de las escuelas de educación media su perior, se seleccionaron dos escuelas públicas y dos privadas de la ciudad de Pachuca, Hidalgo, México.

Se trabajó con alumnos de cuatro preparatorias con la finalidad de realizar un grupo focal en cada una. Esto se hizo para alcanzar la saturación, que de acuerdo con Uwe Flick (citado por Onwuegbuzie, Dickinson y Leech, 2011), es requerida para dar validez a esta herramienta.

Durante la dinámica de grupos focales se realizaron, además de recuperar los datos básicos de las y los alumnos, varias actividades que consideraron la evaluación de las campañas emitidas por el Instituto Nacional de las Mujeres y el Institu to Hidalguense de las mujeres, así como, pedir a los jóvenes que dibujaran de manera sencilla, propuestas que orientaran las campañas sociales para prevenir, atender y erradicar la violencia de género desde su propia concepción de la problemática.

Los dibujos se recuperaron para este trabajo, aunque cabe mencionar que fueron realizados a mano y en corto tiempo, por lo que no se evalúa la calidad artística de los mismos.

Para el análisis de los dibujos recuperados se utilizan las categorías de Roland Barthes (1985): lo denotado, lo connotado y las funciones de anclaje y relevo del mismo autor. Lo denotado corresponde a lo que se observa en la imagen a analizar, es decir, la descripción de la misma; mientras que lo denotado hace referencia al trasfondo de la imagen, lo no dicho de manera abierta. La función de anclaje, contribuye a anclar la imagen a un solo significado, lo que limita la polisemia de la misma, el anclaje puede ser una palabra, un logo o un slogan, y el mayor peso del mensaje lo tiene la imagen. Por otro lado, la función de relevo es más usual en el cómic que en la publicidad, pues implica un mayor uso de texto y la imagen tiene poco peso en el mensaje.

Esquema 1. Modelo de análisis retórico de la imagen de Roland Barthes

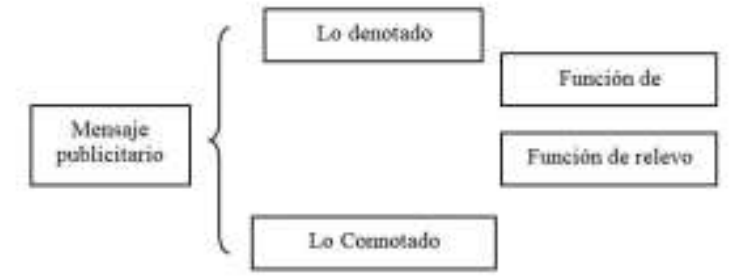

Fuente: Barthes (1982/1986).

\section{Resultados}

Los principales resultados obtenidos de los grupos focales apuntan a que las y los jóvenes tienen poca cercanía con las campañas emitidas por las instituciones o asociaciones civiles, en muchos de los casos no se sienten identificados con las imágenes o los slogans:

Participante: Se necesitan [imágenes] más fuertes ¿no?, para que volteemos a ver.

Participante: Igual (...) algo que sea llamativo ¿no?, porque son así como que (...) equis (sic.).

Las y los participantes no recordaban, en la mayoría de los casos, publicidad social que previniera la violencia de género, algunos lograron recordar algunas imágenes o slogans incompletos pero en realidad no se identificó a la violencia de género como una problemática vigente entre ellos.

El olvido de las campañas por parte de los jóvenes receptores puede estar relacionado con la percepción que tienen de la fuente, tal como lo apunta Hovland (1985), el olvido puede relacionarse con que fuente emisora del mensaje fue descartada inicialmente por considerarse poco fiable. En este caso, la mayoría de las campañas fueron emitidas por instituciones de gobierno durante las administraciones presidenciales de Felipe Calderón (panista) y Enrique Peña Nieto (priista), y durante gobiernos priístas en el estado de Hidalgo, con los cuales la población se sentía poco identificada.

Ahora bien, pese al olvido consciente de las campañas consumidas, los discursos visuales parecen haberse quedado de manera residual:

En este caso, lo "que se recuerda" y "lo que se cree" pueden mantenerse separados al principio, pero si el contenido "se retiene", tras haber quedado olvidada la 
fuente, cabe que ya no se dé por desechado (Hovland, Lumsdaine y Sheffield, 1985).

Lo anterior se observa en la siguiente parte de la dinámica, tal y como se detalla a continuación.

Una vez que se llevó a cabo la revisión de las campañas oficiales, se solicitó a las y los alumnos participantes que hicieran algunos dibujos para proponer imágenes que podrían utilizarse para las campañas contra la violencia de género. Los dibujos debían ser construidos de acuerdo a lo que las y los alumnos consideraran que podría llamar la atención o sobre esta problemática, pese a que habían comentado que no recordaban campañas sobre este tema, las imágenes resultantes concuerdan con lo expuesto arriba, por lo tanto, se puede sostener que su imaginario social sobre la violencia de género, sí se ha visto permeado por los medios aun cuando los receptores lo hayan olvidado aparentemente.

Se detectaron dos vertientes principales: la que corresponde a las representaciones donde se usan imágenes de mujeres golpeadas o en situaciones de violencia física, concordantes con la primera etapa de publicidad social emitida para prevenir, la violencia, que corresponde con la promoción de la denuncia y la visibilización de un solo tipo de agresiones.

Figura 3. Imagen de cuerpo entero de una mujer golpeada en el rostro y con gesto de infelicidad.

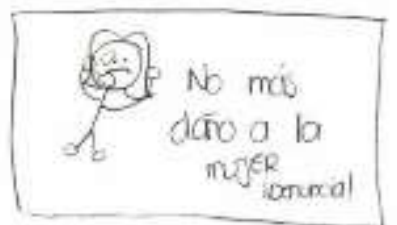

Fuente: Grupos focales realizados para esta investigación, 2014.

En la figura 3, lo denotado muestra un full shotii de una mujer de cabello corto que se lleva las manos a la cara. El rostro presenta lesiones y, los ojos y la boca del dibujo muestran que la mujer está asustada o triste. En este caso, la función que se está utilizando es de relevo, porque el texto es más extenso y no solo ancla la imagen a una interpretación si no que da más información de la misma, el dibujo no lleva el mayor peso del mensaje, aunque podría haberlo tenido si solo se hubiera colocado la frase ¡Denuncia!

Figura 4. Rostro golpeado de una mujer, que termina asesinada

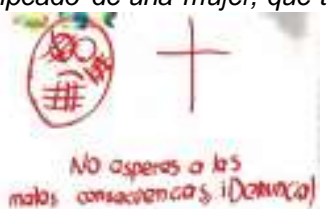

Fuente: Grupos focales realizados para esta investigación, 2014.

Lo denotado en la figura 4 muestra un big close up ${ }^{i v}$ del rostro de una mujer severamente golpeado, con la boca amordazada y una cruz al lado. En la parte inferior se lee la frase: "No esperes a las malas consecuencias, ¡Denuncia!, igual que en la figura anterior, la función que se utiliza es de relevo.

Figura 5. Primer recuadro, mujer golpeada, segundo recuadro mujer feliz con su familia.

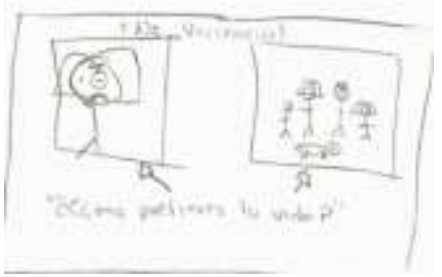

Fuente: Grupos focales realizados para esta investigación, 2014.

En la figura 5, otra vez tenemos el uso de encuadres abiertos, el recuadro está divido en dos espacios que representan escenas diferentes. En el recuadro que se encuentra a la izquierda se presenta una mujer golpeada y asustada, mientras que del lado derecho se observa a una familia feliz. En la parte superior se integra la siguiente frase: "iNo a la violencia!", mientras que en la inferior se agrega la pregunta "¿Cómo prefieres tu vida?" La función que se utiliza es de anclaje, puesto que el mayor peso del mensaje lo lleva la imagen, es decir, aunque no se tuviera el texto, la imagen es lo bastante explícita como para que el receptor entienda el mensaje. En cuanto a lo connotado, las y los alumnos que hicieron este tipo de representaciones, explicaron que ellos consideran que las imágenes deben ser fuertes para que llamen la atención, no contemplaron dentro de las mismas, más que la violencia física y siguen asignando a las mujeres la responsabilidad de solucionar la situ ación a través de la denuncia. De ahí que en la Fig. 5, se observa una pregunta que da al espectador la idea de que las mujeres tienen la posibilidad de decidir entre vivir una vida de violencia o una vida feliz con solo una denuncia, lo que remite a la concepción de la violencia de género como una problemática individual y no cultural cuyos resabios en las vidas de los sujetos que la viven, son inexistentes.

Se observa una coherencia constante con las narrativas promocionadas en los medios, donde la violencia se encasilla en lo físico y se asume que las mujeres que sufren violencia, viven en esta situación lo hacen porque no han "tomado la decisión" de salir de ella:

Estas ideas [...] se combinan e interactúan entre sí, dando lugar a estereotipos sobre los motivos por los cuales los hombres cometen violencia sexual, así como sobre el tipo de niñas y mujeres a las cuales les ocurre, ofreciendo una especie de explicación causal, "Les gusta/lo quieren", "Lo están pidiendo/se lo merecen", "Solo le sucede a cierto tipo de mujeres/familias", "Están mintiendo o exagerando", "Si han sido capaces de mostrar resistencia es que 
podían haberlo evitado", o "Los hombres que cometen este tipo de actos están enfermos, son dementes, están bajo estrés, o fuera de control" (Martínez, 2017: 17).

Tal como apunta Martínez (2017), buscar una explicación causal vinculada con una patología individual, niega el carácter estructural y sistémico que sostiene la violencia de género y en específico, la violencia contra las mujeres, tal y como se mencionó en líneas anteriores. Una de las principales críticas a las campañas que se han emitido para prevenir, atender y erradicar la violencia contra las mujeres, es precisamente la invisibilización del trasfondo cultural de la misma. Lo que ha contribuido a crear un imaginario social sobre la violencia entre las y los jóvenes, a través del consumo mediático de estos discursos.

Dentro de las imágenes que incluyen la figura de una mujer golpeada, además de apelar a las víctimas para que denuncien, también se buscaba la empatía de los públicos insinuando que el agredido podía ser el mismo espectador si era testigo de violencia y no lo denunciaba, tal es el caso de la figura 6, donde en la denotación se observa una mujer tirada en el piso, solicitando ayuda, mientras que a lo lejos, tres personas le observan sin hacernada.

Figura 6. Mujer golpeada solicitando ayuda, gente observando.

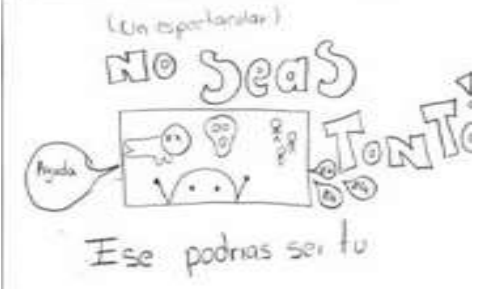

Fuente: Grupos focales realizados para esta investigación, 2014.

En la parte superior del dibujo se lee la frase: "No seas tonta", texto que se complementa en la parte inferior: "Ese podrías ser tú". En esta representación lo denotado ya contempla varios sujetos involucrados en la problemática de violencia, por lo que empezamos a notar una modificación en la concepción de la violencia como un problema individual.

Sin embargo, en el aspecto connotado, el tipo de violencia que se representa, también se encasilla en lo físico y se busca generar empatía a través del miedo a convertirse en víctima y ser ignorado, no se reflexiona sobre un trasfondo cultural de la violencia, y mucho menos si ésta es por cuestiones de género, más bien se centran en la creación de un agresor implícito, que podría en algún momento convertirse en agresor de quien observa.

La segunda vertiente que se observó fue la representación de mujeres felices, que promocionan la denuncia de la violencia, esta imagen crea la idea de una escisión, de un nosotras que no vivimos violencia, refiriéndonos a esas otras víctimas "opacas porque se hacen invisibles cuando no son violentadas, o cuando también lo son, como es el caso de las maltratadas psíquicamente" (Fernández, 2008: 33)

En concordancia con lo anterior, la figura 7, presenta un close $u p^{v}$ de una mujer que invita a las otras a denunciar para acabar con la violencia de género. El rostro representado es el de una joven sonriente, acompaña la imagen un globo o balloon donde se encuentra la siguiente frase: "No permitas ningún tipo de abuso", mientras que en la parte inferior se colocó el texto: "Infórmate y denuncia para acabar con la violencia de género".

Figura 7. Mujer sonriente que invita a denunciar la violencia

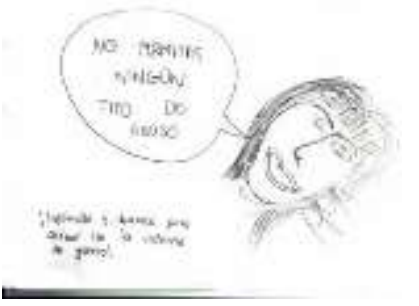

Fuente: Grupos focales realizados para esta investigación. 2014.

Pese a lo positivo de la imagen, en lo connotado se podría interpretar que esta escisión que separa a un as y otras en el ámbito de la violencia crea la idea del "a mí no me va a pasar", se piensa que la violencia de género sólo le ocurre a algunas, ahí que se piense que las mujeres que viven situaciones de violencia pueden superarlas a través de la información, de este modo se construye la imagen de las otras vulnerables y desinformadas, tal y como apunta Martínez (2017), se crea un imaginario de la víctima y del agresor, por ello, en el caso de mujeres activistas o bien informadas, la falta de coherencia entre el imaginario y su situación no les permite reaccionar.

...una de las dificultades para reconocer, identificar y actuar frente a la situación de maltrato y violencia es, entre otras cuestiones, el hecho de que su pareja y agresor no encaje dentro del discurso hegemónico e imaginario sobre los maltratadores (Martínez, 2017).

Finalmente, se observó una tercera representación menos constante, donde las imágenes buscaban incluir tanto a hombres como a mujeres, a la comunidad y a la sociedad. Es decir, en estas representaciones el imaginario social empieza a transformarse, y a contemplar la violencia de género como un problema social que afecta a todos y todas.

En este sentido, la figura 8 denota a dos niños que se encuentran tomados de la mano, uno de sexo femenino y otro de sexo masculino. El niño viste pantalones y camiseta y usa el cabello corto, mientras que la niña usa un vestido y el cabello hasta el hombro, ambos niños 
sonríen. Las dos figuras se encuentran sobre un mapa y un signo de igual. En la parte superior se colocó la frase: "Convivencia sin violencia" y en la inferior: "Tú y yo, somos iguales".

Figura 8. Niño y niña tomados de la mano en globo terráqueo

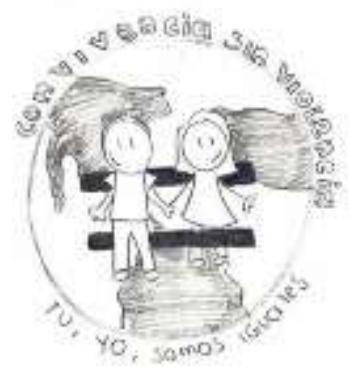

Fuente: Grupos focales realizados para esta investigación, 2014.

Aunque, como ya mencionamos en párrafos anteriores, se empieza a ver la violencia como un problema de hombres y mujeres, en la figura 8 aún se observan vigentes estereotipos de género como lo es el hecho de que el niño vista pantalones, zapatos bajos y use el pelo corto, mientras que la niña usa vestido y zapatos altos, aunado a que dentro del signo de igual, ella queda atrás del chico.

En las figuras 9 y 10 se observa ya una propuesta de diálogo como solución a la violencia y las implicaciones culturales que ésta tiene para la comunidad y la sociedad en general. De este modo en la figura 9, lo denotado muestra un full shot de un chico y a una chica platicando, ambas figuras son del mismo tamaño, no usan un color o vestuario específico, ni tienen características corporales que remitan al sexo, salvo el cabello largo de la joven. A la derecha de la imagen se colocó el siguiente texto: "Por ti, por tu familia, por tu comunidad, di sí a la equidad". La función presente es la de relevo, puesto que la imagen no tiene la suficiente fuerza para sostener todo el mensaje y $\sin$ el texto no tendría sentido, ni se le relacionaría con la problemática de violencia.

Figura 9. Hombre y mujer dialogando sobre equidad

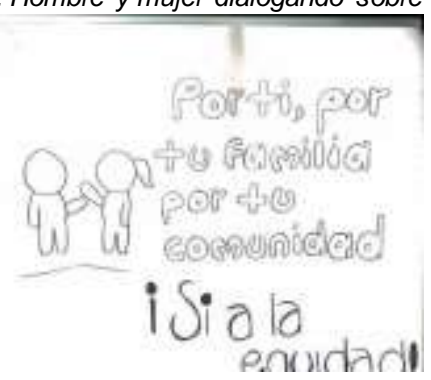

Fuente: Grupos focales realizados para esta investigación, 2014

En lo connotado se promueve la equidad como una vía para una mejor calidad de vida y se propugna por un diálogo en donde tanto hombres como mujeres se ven involucrados en una problemática contextual que afecta a todas $\mathrm{y}$ todos, tanto en relaciones personales como en familiares y comunitarias.

Esta idea se mantiene también en la siguiente figura (10), donde se observa un encuadre de medium shot ${ }^{v i}, y$ a dos personas dialogando, parece que son un hombre y una mujer quienes afirman lo siguiente: "iLa violencia ya no es bienvenida en la sociedad!". La función del texto es de anclaje, puesto que si bien limita la polisemia de la imagen, no brinda mayor información.

Figura 10. Personas dialogando para solucionar problemas

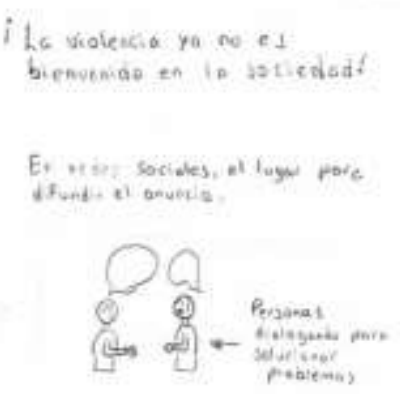

Fuente: Grupos focales realizados para esta investigación, 2014.

Ahora bien, respecto a lo connotado, en la figura 10 se plantea un cambio de paradigma con el slogan: " $\mathrm{La}$ violencia ya no es bienvenida en la sociedad!", es decir, el estudiante que realizó la propuesta reflexionó sobre el hecho histórico que determina que un paradigma violento que funcionó en determinada época es ahora obsoleto por lo que hay que buscar nuevas formas de convivencia a través del diálogo, aunque sin el texto que le acompaña, la imagen tendría una polisemia mu y alta.

\section{Conclusiones}

Mucho se ha discutido sobre la creación de estereotipos que se promueven a través de la publicidad comercial, sin embargo, la publicidad social o la propaganda con fines sociales también incide sobre la percepción que se tiene sobre algo o alguien, quizás, en esta época con mayor preponderancia que la publicidad comercial, puesto que se asume que la publicidad social es elaborada por especialistas, cuyo objetivo es el bien social y por ello los discursos visuales y escritos pueden contar con mayor validez para el espectador.

En este caso, resulta sumamente interesante cómo los jóvenes, pese a que dijeron que no recordaban haber visto campañas de prevención, atención y erradicación de la violencia reiteraron los discursos de los medios, sobre todo en la representación de la violencia física como la única posible de llamar la atención y la otra con la representación discordante de la mujer sonriente hablando de violencia, es decir, se ha conformado un imaginario social sobre lo qué es la violencia y cuándo debes actuar. Se promueve la empatía a través del miedo pero no en una reflexión sobre el daño cultural o 
social que la violencia ocasiona y que refleje los distintos tipos de violencia existentes así como los actores diversos que se ven involucrados en la misma.

Es decir, las y los jóvenes están diciendo a través de las imágenes, que solamente algo con violencia física notable podría convencerlos de hacer algo para aten der esta problemática o que sólo en caso de considerarse como posibles víctimas podrían generar empatía, en este caso, es importante mencionar que desafortunadamente, en una sociedad donde se tiene tanto acceso a la información, el contar con ésta, en lugar de generar atención y prevención, es considerada por los jóvenes como "una barrera protectora" que deriva en un "a mí no me va a pasar".

Ahora bien, pese a que aún permea la reiteración de roles de género y la creencia de que la verdadera violencia sólo es física, también se observa una modificación lenta y gradual del imaginario social donde se empieza a filtrar lentamente la idea de que la violencia es un problema comunitario y social contra el que todas y todos tienen que luchar a través de vías de diálogo y educación formal e informal.

Lo interesante de este estudio es sobre todo la pregu n ta que queda en el aire ¿Cómo representar la violencia sin violencia?, ¿de qué manera se puede contribuir a la conformación de un imaginario social donde se comprenda qué es la violencia, sus diversas formas e implicaciones sociales y culturales sin recurrir al amarillismo de la violencia física o a la discordancia de una mujer son riente hablando de violencia?

También es necesario comentar que en las imágenes representadas se reitera una y otra vez la idea de que la violencia de género únicamente afecta a las mujeres, dejando de lado el hecho de que este tipo de violencia es interseccional y que también se refleja en grupos con orientaciones sexuales diferentes, incluso, en la construcción de modelos de masculinidad hegemónica en niños y niñas.

Ahora bien, para cerrar cabe resaltar que este estudio se llevó a cabo con jóvenes en el año 2014, y que pese a que las campañas de prevención atención y erradicación de la violencia, aún seguían esta constante para 2019, tal y como se observa en la campaña de prevención emitida en 2019, en España; el movimiento feminista, la denuncia en redes a través de performance, paros y las marchas que se llevaron a cabo con motivo del 8 de marzo en 2020, y a causa de la exacerbación de la violencia contra las mujeres, podrían incidir en la representación de la violencia de género en este tipo de publicidad social y sobre todo, en la representación que tienen los jóvenes de la misma. De ahí la importancia de seguir profundizando en los estudios sobre campañas sociales y su repercusión en la construcción de imaginarios sociales en torno a la violencia de género.

\section{Referencias}

Agudelo, Pedro Antonio (2011). “(Des)hilvanar el sentido/los juegos de Penélope" Uni- pluri/versidad, Vol.1, Núm.18.

Barthes Roland (1982/1986) Lo obvio y lo obtuso. Imágenes, gestos y voces. Buenos Aires: Paidós Comunicación.

Castelli, Azul Kikey (2019). Las huellas del discurso. Publicidad social y violencia de género. México: Universidad Autónoma del Estado de Hidalgo.

El país. Campaña fallida. La sucesión de crímenes de violencia de géne ro casa mal con un anuncio en el que el concepto de malos tratos va asociado a unas mujeres sonriendo. 7 de Agosto de 2019. https://elpais.com/elpais/2019/08/07/opinion/1565201895_689582.htm 1 [último acceso: 1 de Septiembre de 2019].

Escobar, Jazmine, y Bonilla-Jiménez, Francy Ivonne (2009). "Grupos focales: una guía conceptual y metodológica”. Cuadernos hispanoamericanos de psicología. Vol. 9, Nun. 1, pp-54-65.

Fernández, Ana María (2016). "La imaginación colectiva y anónima". Diferencias. Revista de teoría social contemporánea. No.2, Año 2, mayo 2016,pp.194-213.

Fernández, Diana (2008). "Gramáticas de la publicidad sobre la violencia : la ausencia del empoderamiento tras el ojo morado y la sonrisa serena”. Feminismo/s. Núm.11, junio, 2008, pp. 15-39.

Hovland, Carl, Arthur Lumsdaine y Fred Sheffield. (1985) "Efectos a corto y a largo plazo en el caso de los films de «orientación»o propaganda". En Moragas, Miquel. Sociología de la comunicación de masas. I Escuelas y autores, pp. 238-251. Barcelona: Gusta vo Gili.

Kitzinger, Jenny (1995). "Qualitative Research: Introducing focus group". Qualitative Research: Introducing focus group. 29 de Julio de 1995, fecha de consulta: 20 de enero de 2014. http://www.bmj.com/content/311/7000/299.

Krueger, Richard (1994). Focus Group: a principal guide for applied research. Estados Unidos: Newbury Park CA.

López Lita, Rafael y Bernad, Estela (2007), "Publicidad, medios de comunicación y segregación ocupacional de la mujer: perpetuación y superación de los estereotipos de género y sus consecuencias en el mercado de mano de obra". Revista del Ministerio de Trabajo y Asuntos Sociales, Núm. 67, pp. 213-225.

Piñeiro M. Teresa (2010). "Estereotipos femeninos en la publicidad: la utilización del sexolecto como un atributo caracterizador". Cuadernos Kóre. Revista de historia y pensamiento de género. El género en controversia. Rocío Orsi (ed.). Vol. 1, No 2. Primavera 2010, pp. 156178.

Martínez Portugal, Tania (2017). Transformando imaginarios sobre violencia sexista. País Vasco: Emakunde.

Onwuegbuzie, Anthony J., Wendy B. Dickinson, Nancy L. Leech, y Annmarie G. Zoran. (2011). "Un marco cualitativo para la recolección y análisis de datos en la investigación basada en grupos focales". Paradigmas, ene.-jun., 2011, Vol. 3, No. 1, pp. 127-157.

Ramírez, Miguel Ángel (2011). “Grupos focales”. Revistas de negocios, pp. $70-74$

file:///C:/Users/USUARIO/Downloads/Miguel\%20\%C3\%81ngel\%20R am\%C3\%ADrez__CESUN\%20Universidad\%20maramirez@cesun.e du.mx.pdf

Staff, Indigo. Cambio de percepción. 8 de Septiembre de 2013. https:/www.reporteindigo.com/reporte/cambio-de-percepcion/. 


\section{NOTAS}

¿ Véase. Castelli (2019), citado en las referencias.

ii Véase. Castelli (2019), citado en las referencias.

iii Encuadre que abarca de la cabeza a los pies del sujeto.

${ }^{\text {iv }}$ Encuadre cerrado que abarca únicamente de la barbilla a la frente del

sujeto presentado.

${ }^{v}$ Encuadre que abarca delcuello a la cabeza del sujeto que se representa.

${ }^{v i}$ Encuadre que abarca de la cintura a la cabeza delsujeto que representa. 